\title{
In Vitro Evaluation of the Antimethanogenic Potency and Effects on Fermentation of Individual and Combinations of Marine Macroalgae
}

\author{
Robert D. Kinley ${ }^{1}$, Matthew J. Vucko²${ }^{2}$, Lorenna Machado², Nigel W. Tomkins ${ }^{1}$ \\ ${ }^{1}$ CSIRO Agriculture, Australian Tropical Science \& Innovation Precinct, James Cook University, Townsville, Australia \\ ${ }^{2} \mathrm{MACRO}-\mathrm{The}$ Centre for Macroalgal Resources and Biotechnology, College of Marine and Environmental Sciences, \\ James Cook University, Townsville, Australia \\ Email: rob.kinley@csiro.au
}

How to cite this paper: Kinley, R.D., Vucko, M.J., Machado, L. and Tomkins, N.W. (2016) In Vitro Evaluation of the Antimethanogenic Potency and Effects on Fermentation of Individual and Combinations of Marine Macroalgae. American Journal of Plant Sciences, 7, 2038-2054.

http://dx.doi.org/10.4236/ajps.2016.714184

Received: September 26, 2016

Accepted: October 16, 2016

Published: October 19, 2016

Copyright (๑) 2016 by authors and Scientific Research Publishing Inc. This work is licensed under the Creative Commons Attribution International License (CC BY 4.0).

http://creativecommons.org/licenses/by/4.0/ (c) (i) Open Access

\begin{abstract}
Contribution of ruminants to total greenhouse gas emissions in Australia is approximately $10 \%$ and likely to increase with demand for livestock products, thus an efficient method of mitigation must be implemented. The red marine macroalgae Asparagopsis taxiformis reduces enteric methane production by up to $99 \%$ in vitro. Other macroalgae with less potent antimethanogenic properties may complement inclusion of Asparagopsis in livestock feeds. Adoption of environmental based changes in livestock systems must provide benefits to producers if change in management is to be adopted. This study used $72 \mathrm{~h}$ in vitro fermentations with rumen inoculum to characterize and rank seven species of macroalgae at low inclusion that previously demonstrated some degree of antimethanogenesis at higher inclusion concentration. The seven were assessed at 5\% inclusion (OM basis) and in combination with Asparagopsis to evaluate beneficial effects on fermentation. When tested individually, improvements in volatile fatty acids were generally observed, however, minimal effect on gas production and no clear justification for a ranking order were demonstrated. When tested in combination with Asparagopsis, the effects on fermentation were dominated by presence of Asparagopsis at 2\% and no further benefits demonstrated. Therefore, Asparagopsis remains the only macroalga inducing near elimination of methane in vitro and benefit of combinations with other macroalgae evaluated in this study was not demonstrated. However, combination with high protein macroalgae is proposed to provide productivity enhancement during seasonal lows in grass quality and thus reduce methane emissions intensity providing a stronger conduit for environmental responsibility while increasing productivity.
\end{abstract}

\section{Keywords}

Asparagopsis, Methane, Rumen, Seaweed, Algae 


\section{Introduction}

A large proportion of methane $\left(\mathrm{CH}_{4}\right)$ emitted into the atmosphere derives from agriculture, and specifically ruminant enteric fermentation which contributes approximately $28 \%$ of global anthropogenic $\mathrm{CH}_{4}$ emissions [1].

Ruminants rely on a complex rumen microbial consortium of bacteria, protozoa, archaea, fungi, and bacteriophages [2] associated with fermentation of feed. Fermentation of fibrous and nitrogenous feedstuff results in the production of volatile fatty acids (VFA) and microbial protein, used by the animal for growth, metabolism, and productivity [3]. During fermentation, carbon dioxide $\left(\mathrm{CO}_{2}\right)$ and hydrogen $\left(\mathrm{H}_{2}\right)$ are utilized by methanogenic archaea in the reductive methanogenesis pathway, which reduces partial $\mathrm{H}_{2}$ pressure, but also results in $\mathrm{CH}_{4}$ being emitted into the atmosphere [3]. Low $\mathrm{CH}_{4}$ producing ruminants tend to be more productive and increasing productivity of animals could also lessen $\mathrm{CH}_{4}$ emissions [4]. As a result, many strategies are being evaluated to mitigate enteric methanogenesis, including vaccines, bacteriocins and probiotics, bacteriophage therapy, genetic selection, feeding management and feed additives, and plant secondary metabolites [4].

Feed management and additives such as high-quality forages, grains, ionophores, fats, yeasts, enzymes, microbes, plant extracts and algae have the potential for $\mathrm{CH}_{4}$ abatement [5]. Algae products can improve ruminant health and productivity [6] [7], increase feed quality [8], and inhibit methanogenesis [9]. However, reducing enteric methanogenisis is challenging, and to be adopted as a methodology it needs to be sustainable, practical, economically viable, and improve animal productivity [4]. Recently, the marine macroalgae Asparagopsis taxiformis ([Delile] Trevisan de Saint-Léon 1845; Asparagopsis) has demonstrated effective inhibition of $\mathrm{CH}_{4}$ production in vitro at a dose of $2 \%$ of substrate organic matter (OM). In addition, Asparagopsis maintains the apparent in vitro degradability of OM (IVD-OM), and increases propionate but with a concomitant decrease of acetate [10] [11]. These rumen fermentation parameters are important indicators of fermentation efficiency [12]. Some other marine macroalgae that also reduce $\mathrm{CH}_{4}$, but to a lesser extent than Asparagopsis, have demonstrated better anaerobic fermentation in vitro compared to equal supplementation (17\%) with cotton seed meal by increasing the concentration of total VFA (TVFA) when included with a low-quality grass substrate [13]. Therefore, it may be possible to improve rumen fermentation using combinations of macroalgae at practical dose concentrations when paired with Asparagopsis by increasing VFA production and improving the VFA profile.

It was hypothesised that macroalgae demonstrating $\mathrm{CH}_{4}$ abatement in vitro at high dose concentrations would maintain antimethanogenesis at variable potency at low dose concentrations, and that when combined with the highly potent Asparagopsis they would enhance rumen fermentation. The aim of Experiment 1 was to rank seven select macroalgae for their potential as antimethanogenic feed additives using dose concentrations practical for livestock feeding, and establish their effects on fermentation parameters. The aim of Experiment 2 was to evaluate combining the seven macroalgae 
with Asparagopsis to determine the effect of the combinations on methanogenesis and potential benefits to VFA production.

\section{Materials and Methods}

\subsection{Selection and Preparation of Macroalgae and Rhodes Grass Substrates}

The macroalgae species were selected to represent the major groups of marine macroalgae (red, brown, green) based on their demonstrated ability to decrease enteric $\mathrm{CH}_{4}$ andimprove fermentation [13] and are listed in Table 1. The biomass was sourced from either large scale culture at the Centre for Macroalgal Resources and Biotechnology (MACRO) James Cook University (JCU) in Townsville QLD (19.33 $\left.{ }^{\circ} \mathrm{S} ; 146.76^{\circ} \mathrm{E}\right), \mathrm{Pa}$ cific Reef Fisheries in Ayr QLD (PRF; $19.58^{\circ} \mathrm{S}, 147.40^{\circ} \mathrm{E}$ ), or intertidal flats near Townsville Qld at Nelly Bay (NB; $19^{\circ} 16^{\prime} \mathrm{S} ; 146^{\circ} 85^{\prime} \mathrm{E}$ ) with GBRMPA permit GO2/20234.1, or Rowes Bay (RB; $19^{\circ} 23^{\prime} \mathrm{S} ; 146^{\circ} 79^{\prime} \mathrm{E}$ ) with DPIF permit 103,256 . The individual algae and sources were Caulerpa taxifolia ([M.Vahl] Agardh 1817; NB), Cladophora patentiramea ([Montagne] Kützing 1849; PRF), Cystoseria trinodis ([Forsskål] Agardh 1820; NB), Dictyota bartayresii (Lamouroux 1809; RB), Padina australis (Hauck 1887; RB), Sargassum flavicans ([Mertens] Agardh 1820; NB) and Ulva ohnoi (Hiraoka and Shimada 2004; MACRO).

Macroalgae were rinsed and centrifuged in a commercial washing machine at 1000 $\mathrm{rpm}$ for $5 \mathrm{~min}$ at ambient temperature to remove excess water. The biomass was freezedried (VirTis Benchtop 2K; Warminster PA, USA) at $-55^{\circ} \mathrm{C}$ and $120 \mu$ bar for minimum $48 \mathrm{~h}$, then milled to pass a $1 \mathrm{~mm}$ sieve and stored at $-20^{\circ} \mathrm{C}$. The basal substrate was Rhodes grass (Chloris gayana) with neutral detergent fibre (NDF) of $645 \mathrm{~g} \cdot \mathrm{kg}^{-1} \mathrm{dry}$ matter (DM) and acid detergent fibre (ADF) of $315 \mathrm{~g} \cdot \mathrm{kg}^{-1} \mathrm{DM}$. The DM content of the various biomass was determined by drying at $105^{\circ} \mathrm{C}$ to constant weight and the $\mathrm{OM}$ content was determined by the combustion for $8 \mathrm{~h}$ at $550^{\circ} \mathrm{C}$ [14]. Crude protein and

Table 1. Compositional parameters of the macroalgae and Rhodes grass hay.

\begin{tabular}{clllll}
\hline Substrate & Macroalgae Type & DM & OM & CP & GE $^{\text {a }}$ \\
\hline Asparagopsis taxiformis & Rhodophyta (Red) & $923^{\mathrm{b}}$ & 797 & 278 & 17 \\
Caulerpa taxifolia & Chlorophyta (Green) & 929 & 663 & 163 & 13 \\
Cladophora patentiramea & Chlorophyta (Green) & 939 & 564 & 120 & 11 \\
Cystoseria trinodis & Ochrophyta (Brown) & 909 & 650 & 92 & 12 \\
Dictyota bartayresii & Ochrophyta (Brown) & 940 & 658 & 90 & 13 \\
Padina australis & Ochrophyta (Brown) & 931 & 532 & 55 & 9 \\
Sargassum flavicans & Ochrophyta (Brown) & 919 & 646 & 42 & 12 \\
Ulva ohnoi & Chlorophyta (Green) & 898 & 695 & 215 & 12 \\
Rhodes grass & - & 916 & 804 & 167 & 17 \\
\hline
\end{tabular}

a. MJ $\cdot \mathrm{kg}^{-1}$ DM.b. Parameters presented as $\mathrm{g} \cdot \mathrm{kg}^{-1}$ unless otherwise stated. DM, dry matter; OM, organic matter; CP, crude protein. 
gross energy quantification were determined as previously described by [13]. Crude protein of the macroalgae was based on total nitrogen (wt \%) content using a nitrogen factor of 5 for the macroalgae [15] and 6.25 for the Rhodes grass.

\subsection{Research Animals and Preparation of Rumen Fluid Inoculum}

Rumen fluid inoculum (RF) was collected from four fistulated Brahman steers (Bos indicus, LW $460 \pm 20 \mathrm{~kg}$ ) fitted with $10 \mathrm{~cm}$ Bar Diamond (Parma, OH, USA) rumen cannulas. The steers were maintained at the College of Public Health, Medical and Veterinary Sciences of JCU according to current guidelines [16] and approved by the CSIRO animal ethics committee (A5/2011). The steers were maintained on Rhodes grass hay ad libitum for 6 months before the collection of RF, which was extracted $2 \mathrm{~h}$ after morning feeding by sampling from four quadrants of the rumen and hand squeezing to completely fill pre-warmed $1 \mathrm{~L}$ stainless steel thermos flasks.

\subsection{Inoculation of in Vitro Fermentations}

The RF was pooled and immediately processed by filtration through a $0.5-\mathrm{mm}$ sieve and combined with incubation buffer (GVB) [17] at a ratio of 1:4 (RF:GVB). Throughout the inoculation process the RF buffer fermentation media (RFB) was maintained at $39^{\circ} \mathrm{C}$ and continuously mixed at $30 \%-35 \%$ of maximum vortex speed (Major Science SWB $20 \mathrm{~L}^{-3}$; Saratoga, CA, USA) to ensure RFB homogeneity between individual fermentations. Anaerobic conditions were maintained with high purity $\mathrm{N}_{2}\left(\mathrm{HPN}_{2}\right.$; BOC, Wetherill Park NSW, AUS). A Dose-It pump (Integra Biosciences, Hudson NH, USA) was used to aspirate $125 \mathrm{~mL}$ of RFB into each incubation bottle containing the macroalgae and Rhodes grass substrates. The substrate and macroalgae were preloaded prior to RF collection into $250 \mathrm{~mL}$ Simax incubation bottles (Sázava, CZE). Each bottle was purged $\mathrm{HPN}_{2}$, capped, and warmed to $39^{\circ} \mathrm{C}$. The bottles were sealed with an Ankom RF1 gas production module (Macedon NY, USA), placed in mixing incubators (Ratek OM11; Boronia VIC, AUS), and maintained at $39^{\circ} \mathrm{C}$ and oscillating at $85 \mathrm{RPM}$ for $72 \mathrm{~h}$.

\subsection{Experimental Design}

Experiment 1 was conducted to rank macroalgae according to their antimethanogenic potency and effects on rumen fermentation parameters. This was accomplished using in vitro fermentation batch culture (Ankom) to determine effects of macroalgae inclusion on total gas (TGP), $\mathrm{CH}_{4}$, and VFA production, and IVD-OM. A series of four incubation periods were completed and consisted of $1.0 \mathrm{~g}$ of Rhodes grass substrate as control and appropriate quantities of each macroalga to achieve a dose concentration of $5 \%$ of the substrate OM according to the biomass composition described in Table 1. Fermentations were also completed as controls (no macroalgae), a positive-control (Pcontrol) of Asparagospis at 2\%, and RFB blanks. The inclusion of the macroalgae at 5\% was determined as an arbitrary feasible level of feeding for livestock and based on results previously described for inclusion approaching 20\% [13]. The inclusion of $A s$ paragopsis at $2 \%$ was set based on previously determined optimum dose for this sea- 
weed in rumen fermentations [10] [11]. The seven macroalgae and Asparagopsis were randomly assigned to the four incubation periods $(n=3)$, and controls and blanks were included in all periods $(n=4)$. Within each incubation period, there was duplication of each macroalga, and controls and blanks at each sampling time point $(12,24,48$, and 72 h).

Experiment 2 was conducted to determine if the seven macroalga when combined with Asparagopsis studied in Experiment 1 would benefit in vitro rumen fermentation. This was accomplished using the same fermentation techniques as Experiment 1. A series of five incubation periods were completed and consisted of $1.0 \mathrm{~g}$ of Rhodes grass substrate as control and appropriate quantities of each macroalga to achieve a dose concentration of 5\% (OM basis) in combination with Asparagopsis at 2\% according to the biomass composition described in Table 1. Fermentations were also completed as controls (no macroalgae), a P-control of Asparagospis at 2\%, and RFB blanks. The seven combinations and Asparagospis were randomly assigned to the five periods ( $n=$ 3 ), and controls and blanks were included in all periods $(n=5)$. Within each incubation period, there was duplication of each macroalgae combination, and controls and blanks at each sampling time point $(12,24,48$, and $72 \mathrm{~h})$.

\subsection{Total Gas and Methane Production}

The fermentation methods used in this study were similar to [18] but using the Ankom RF1 system and gas analysis as described by [10]. Pressure accumulation in the incubation bottles was measured continuously and recorded every $20 \mathrm{~min}$. The maximum fermentation pressure inside the incubation bottle was set to 3 psi which, when exceeded, caused venting for $250 \mathrm{~ms}$ and the pressure change accounted in the cumulative pressure recording. Gas pressure was measured every $60 \mathrm{~s}$ and cumulative pressure was recorded at $20 \mathrm{~min}$ intervals. The TGP was expressed as $\mathrm{mL}$ of gas produced per gram of substrate $\mathrm{OM}\left(\mathrm{mL} \cdot \mathrm{g}^{-1} \mathrm{OM}\right)$ by application of the natural gas law to the accumulation of the recorded gas pressure while accounting for individual bottle volume.

In vitro $\mathrm{CH}_{4}$ production was quantified in time series at multiple time points of 12 , 24, 48 and $72 \mathrm{~h}$ during the fermentation. The $\mathrm{mL}$ of $\mathrm{CH}_{4} \mathrm{~g}^{-1}$ of substrate $\mathrm{OM}$ was estimated using concentrations in headspace at the time series points while assuming homogeneity of headspace gas. The headspace samples were collected into $10 \mathrm{~mL}$ Labco Exetainer vials (Lampeter, GBR) and quantified using gas chromatography (GC) according to parameters described by [10]. Concentrations of $\mathrm{CH}_{4}$ in headspace gas were converted to $\mathrm{mL} \cdot \mathrm{g}^{-1}$ substrate OM based on TGP at the relative time series points and assuming headspace homogeneity at system venting [19].

\subsection{Apparent in Vitro Digestible Organic Matter and Volatile Fatty Acids}

The IVD-OM and VFA production was determined as described by [10] and quantified to coincide with $\mathrm{CH}_{4}$ determinations at each time series point. Each fermentation was chilled to cease bacterial activity and the in vitro fluid (IVF) was then vacuum filtered through a Duran No. 1 porosity glass fritted crucible containing a $0.5 \mathrm{~cm}$ layer of sand 
filtration aid. The $\mathrm{pH}$ was measured on the filtrate. Crucibles and wet residue were oven-dried to constant weight at $105^{\circ} \mathrm{C}$ for $\mathrm{DM}$ determination. Residue $\mathrm{OM}$ was determined as loss on ignition in a muffle furnace at $550^{\circ} \mathrm{C}$ for $8 \mathrm{~h}$ [14].

The TVFA accumulated in the IVF were quantified after termination of fermentation. Preparation of IVF prior to GC analysis consisted of addition $4 \mathrm{~mL}$ of IVF to $1 \mathrm{~mL}$ of $20 \%$ metaphosphoric acid containing $11 \mathrm{mM}$ of 4 -methylvaleric acid (Sigma-Aldrich; Castle Hill NSW, AUS) providing $2.2 \mathrm{mM}$ internal standard. The samples were mixed and stored at $-20^{\circ} \mathrm{C}$ until a $1.5 \mathrm{~mL}$ subsample was centrifuged for $15 \mathrm{~min}$ at 13,500 rpm and $4^{\circ} \mathrm{C}$ (Labnet Prism R; Edison NJ, USA). The supernatant was filtered through $0.2 \mu \mathrm{m}$ PTFE syringe tip filters (Agilent; Santa Clara, CA, USA) and quantified by GC according to parameters described by [10].

\subsection{Statistical Analysis}

Two-factor repeated-measures permutational analysis of variance (PERMANOVA) was used to test for significant differences in TGP $\mathrm{CH}_{4}$ production, and IVD-OM over time. A one-factor PERMANOVA was used to test for significant differences in the production of VFA between treatments (fixed factor) using Primer 6 (version 6.1.13; [20] statistical software and PERMANOVA+ (version 1.0.3) [21]. For PERMANOVA, Bray-Curtis similarity matrices were produced using the untransformed raw data and dummy variables $(0.0001)$ were used to account for zero values. The $P$-values were calculated from 999 (TGP) and 9,999 ( $\mathrm{CH}_{4}$, IVD-OM, and VFAs) random permutations. Pair-wise a posteriori comparison was used to determine significant groupings, where applicable. For PERMANOVA, differences were considered significant if $P<0.05$. The TGP data were also fitted with generalized additive models (GAM) using cubic regression spline smoothers to predict the relationship and examine differences between TGP over time. The generalized additive models were produced using the mgcv package within the R language (version 3.0.1) [22]. Goodness-of-fit of the individual smoothers was quantified using the hydroGOF package within the $\mathrm{R}$ language and was assessed from the proportion of variance in the data that was accounted for by the model $\left(r^{2}\right)$ [23].

\section{Results}

\subsection{Experiment 1: Ranking}

Based on predictions of the GAM, which had a high goodness-of-fit $\left(\mathrm{r}^{2}>0.97\right)$, there was a significant difference $(P<0.001)$ in TGP in the fermentations over $72 \mathrm{~h}$ (Figure 1). In addition, the TGP reached its plateau approaching $48 \mathrm{~h}$ in all fermentations and the Asparagopsis induced a lower TGP rate compared with all other treatments $(P<$ 0.001). There was no significant difference in cumulative TGP between the seven macroalgae with inclusion at 5\% (OM basis) and the Rhodes grass control after $72 \mathrm{~h}$ of fermentation. The TGP for all macroalgae other than Asparagopsis ranged between 171 and $176 \mathrm{~mL} \cdot \mathrm{g}^{-1} \mathrm{OM}$, representing an insignificant $2.4 \%-4.8 \%$ reduction in TGP com- 

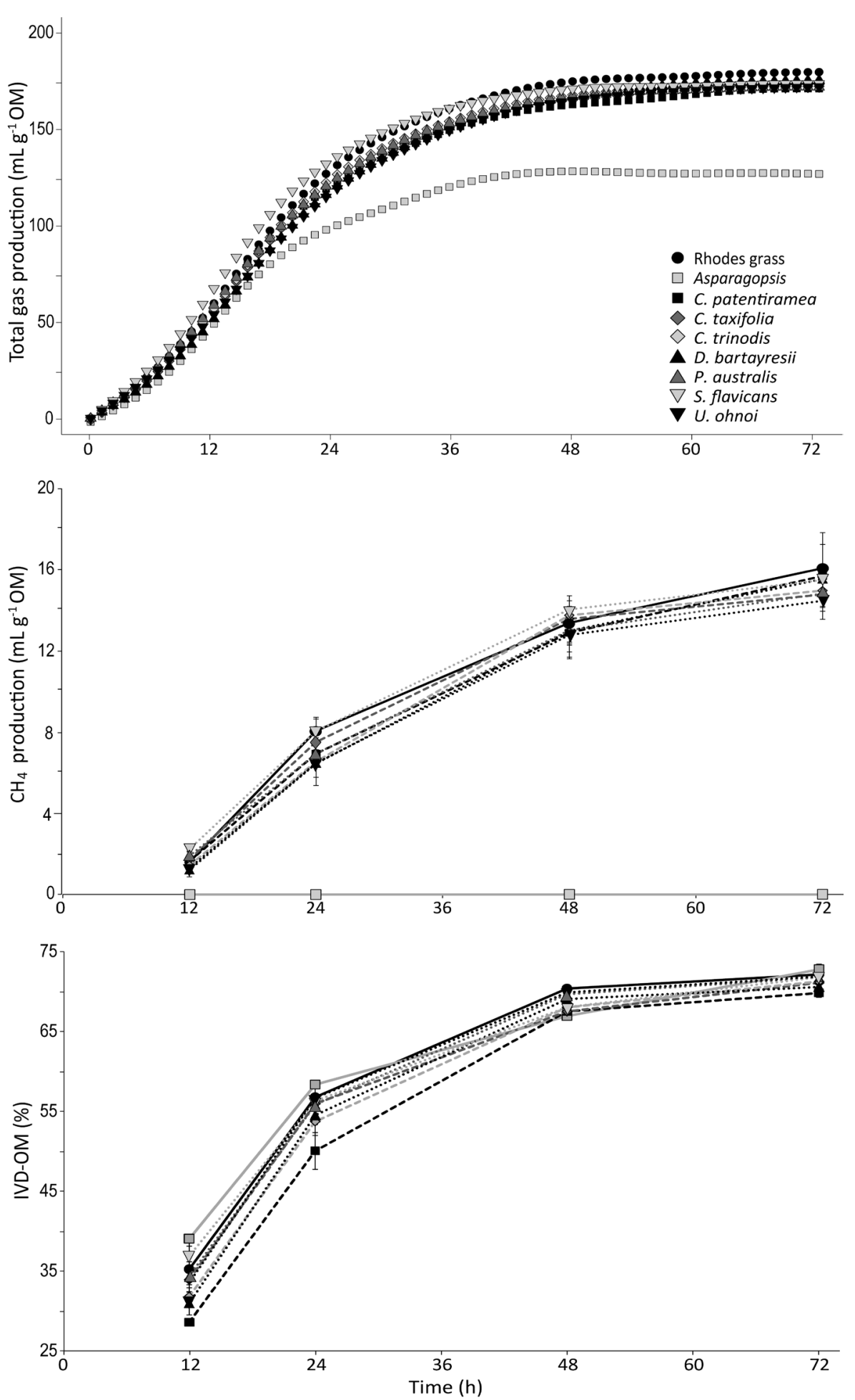

Figure 1. The effect of inclusion of seven different macroalgae on gas production and substrate digestibility over $72 \mathrm{~h}$ of in vitro fermentation with rumen fluid. From top down: Total gas production (TGP); $\mathrm{CH}_{4}$ production; and apparent in vitro digestibility (IVD-OM). The Rhodes grass control substrate was equal in all fermentations, the Asparagopsis control was included at a concentration of $2 \%$ of substrate $\mathrm{OM}$, and the other seven macroalgae included at $5 \%$. No \pm SE is presented for TGP because SE was smaller than the symbols. 
pared to the Rhodes grass control $\left(180 \mathrm{~mL} \cdot \mathrm{g}^{-1} \mathrm{OM}\right)$. However, the Asparagopsis at 2\% had significantly less TGP $\left(127 \mathrm{~mL} \cdot \mathrm{g}^{-1} \mathrm{OM}\right)$ representing a $26 \%-29 \%$ reduction compared to all other macroalgae and controls.

The $\mathrm{CH}_{4}$ production as affected by inclusion of the seven macroalgae other than $A s$ paragopsis was not altered significantly compared to the Rhodes grass control during the course of the $72 \mathrm{~h}$ incubations (Figure 1). The rate of $\mathrm{CH}_{4}$ production as defined by time series headspace sampling was variable in the same manner as for TGP. The only significant reduction in $\mathrm{CH}_{4}$ was induced by Asparagospis in the same way as previously demonstrated [10] and no detectable $\mathrm{CH}_{4}$ was produced. The $\mathrm{CH}_{4}$ production from the other fermentations ranged from a low of $14 \mathrm{~mL} \cdot \mathrm{g}^{-1} \mathrm{OM}$ to a high of 16 $\mathrm{mL} \cdot \mathrm{g}^{-1} \mathrm{OM}$ for $U$. ohnoi and the Rhodes grass control, respectively.

A typical pattern of IVD-OM increasing with time was demonstrated with or without macroalgae (Figure 1), however, the rate of digestion of the substrate varied between treatments in the first half of the fermentation period $(P=0.004)$. Asparagospis induced the earliest onset of substrate degradation in the same fashion as demonstrated by [10] for Asparagopsis at dose concentrations $\leq 5 \%$ of substrate OM. The C.patentiramea was the slowest to achieve maximum rate of IVD-OM. Approaching $48 \mathrm{~h}$, IVD-OM in all the fermentations coalesced, and after $72 \mathrm{~h}$ had similar IVD-OM ranging from a low of $70 \%$ to a high of $72 \%$ for C. patentiramea and the Asparagopsis, respectively. In the absence of macroalgae the IVD-OM for the Rhodes grass control was $72 \%$.

In Experiment 1 the series of in vitro fermentations of the seven macroalgae or $A s$ paragopsis $\mathrm{P}$-control did not induce significant differences between any of the treatments or Rhodes grass control for TVFA $(P=0.093)$ or propionate $(P=0.098)$. However, fermentations including the Asparagopsis were significantly lower for acetate ( $P=$ $0.002)$ and higher for butyrate $(P=0.004)$ compared to the other fermentations (Table 2). A significant increase in propionate and butyrate with $2 \%$ Asparagopsis inclusion has been previously reported [10], however this feature was slightly dampened in the present study for propionate but confirmed the previously observed butyrate concentrations. Compared to the Rhodes grass control, after $72 \mathrm{~h}$ of fermentation the macroalgae induced marginal reductions in TVFA on a molar concentration basis from a low of $9 \%$ to a high of $23 \%$ for D. bartayresii and C. patentiramea, respectively, and Asparagopsis reduced TVFA by $22 \%$. The production of acetate was marginally reduced by a low of $10 \%$ to a high of $24 \%$ by inclusion of $D$. bartayresii and C. patentiramea, respectively, and a significant $44 \%$ with Asparagopsis, respectively. Conversely, propionate was marginally decreased by a low of $5 \%$ to a high of $24 \%$ with inclusion of $D$. bartayresii and C. patentiramea, respectively, and increased by $9 \%$ with Asparagopsis. The production of butyrate was marginally decreased by a low of $11 \%$ to a high of $37 \%$ for D. bartayresii and C. patentiramea, respectively, and significantly increased by $76 \%$ with Asparagopsis.

There were not adequate differences in TGP, $\mathrm{CH}_{4}$, or VFA production to justify well defined ranking for the seven macroalgae evaluated. Clearly, none of the seven macro- 
Table 2. The effect of inclusion of seven macroalgae species on accumulation of volatile fatty acids after $72 \mathrm{~h}$ of in vitro fermentation with rumen fluid. The Rhodes grass control substrate was equal in all fermentations, the Asparagopsis P-control was included at $2 \%$ of substrate OM, and the other seven macroalgae included at $5 \%$.

\begin{tabular}{ccccc}
\hline \multicolumn{5}{c}{ Volatile Fatty Acids $(\mathrm{mM})$} \\
\hline Treatment & Total & Acetate & Propionate & Butyrate \\
\hline Rhodes grass & $43.87 \pm 0.82$ & $28.88 \pm 0.41$ & $11.62 \pm 0.32$ & $1.86 \pm 0.06$ \\
Asparagopsis taxiformis & $34.19 \pm 0.50$ & $16.28 \pm 0.41^{\mathrm{a}}$ & $12.65 \pm 0.10$ & $3.27 \pm 0.11^{\mathrm{a}}$ \\
Caulerpa taxifolia & $38.69 \pm 0.92$ & $25.01 \pm 0.28$ & $10.86 \pm 0.57$ & $1.51 \pm 0.23$ \\
Cladophora patentiramea & $33.81 \pm 3.17$ & $22.10 \pm 2.09$ & $9.46 \pm 1.02$ & $1.17 \pm 0.17$ \\
Cystoseria trinodis & $38.73 \pm 3.07$ & $24.85 \pm 2.51$ & $11.03 \pm 0.44$ & $1.58 \pm 0.26$ \\
Dictyota bartayresii & $40.04 \pm 1.16$ & $26.11 \pm 1.21$ & $11.05 \pm 0.46$ & $1.66 \pm 0.23$ \\
Padina australis & $37.24 \pm 0.35$ & $23.66 \pm 0.57$ & $10.71 \pm 0.40$ & $1.56 \pm 0.20$ \\
Sargassum flavicans & $37.32 \pm 1.12$ & $23.97 \pm 0.62$ & $10.64 \pm 0.47$ & $1.44 \pm 0.28$ \\
Ulva ohnoi & $37.01 \pm 3.63$ & $24.02 \pm 2.72$ & $10.22 \pm 0.91$ & $1.45 \pm 0.14$ \\
\hline
\end{tabular}

a. Significant at $P<0.05$.

algae at 5\% of substrate $\mathrm{OM}$ compares to Asparagopsis at $2 \%$ for $\mathrm{CH}_{4}$ abatement without detriment to IVD-OM during in vitro fermentation. Therefore based solely on numerical $\mathrm{CH}_{4}$ abatement the ranking order from lowest to highest $\mathrm{CH}_{4}$ produced is as follows: 1) U. ohnoi; 2) C. taxifolia; 3) P. australis; 4) C. trinodis, 5) D. bartayresii; 6) $S$. flavicans, 7) C. patentiramea.

\subsection{Experiment 2: Combinations}

Similar to the results of Experiment 1, based on predictions of the GAM, which had a high goodness-of-fit $\left(r^{2}>0.98\right)$, there was a significant difference $(P<0.001)$ in TGP in the fermentations over $72 \mathrm{~h}$ (Figure 2). In addition, the TGP reached its plateau approaching $48 \mathrm{~h}$ in all fermentations, however, in contrast with Experiment 1, the combination treatments were equivalent to the Asparagopsis P-control at 2\% of substrate $\mathrm{OM}$ in the reduction of TGP, but all were significantly different from the Rhodes grass control $(P<0.001)$ after $72 \mathrm{~h}$ of fermentation. The TGP for the combinations ranged between 124 and $136 \mathrm{~mL} \cdot \mathrm{g}^{-1} \mathrm{OM}$ representing a significant $28 \%$ - 34\% reduction in TGP compared to the Rhodes grass control (188 mL.g $\left.{ }^{-1} \mathrm{OM}\right)$. The Asparagopsis induced a TGP of $134 \mathrm{~mL} \cdot \mathrm{g}^{-1} \mathrm{OM}$ and therefore a $28 \%$ reduction, similar to the combinations demonstrating an overwhelming effect of Asparagopsis when combined with other macroalgae.

The $\mathrm{CH}_{4}$ production as affected by inclusion of the seven macroalgae combined with Asparagopsis was not different compared to the Asparagopsis alone during the course of the $72 \mathrm{~h}$ incubations (Figure 2). In the absence of macroalgae the fermentation initiated production of $\mathrm{CH}_{4}$ immediately after inoculation with $\mathrm{RFB}$, however, the inclusion of the macroalgae combinations completely inhibited $\mathrm{CH}_{4}$ until $48 \mathrm{~h}$ when trace 

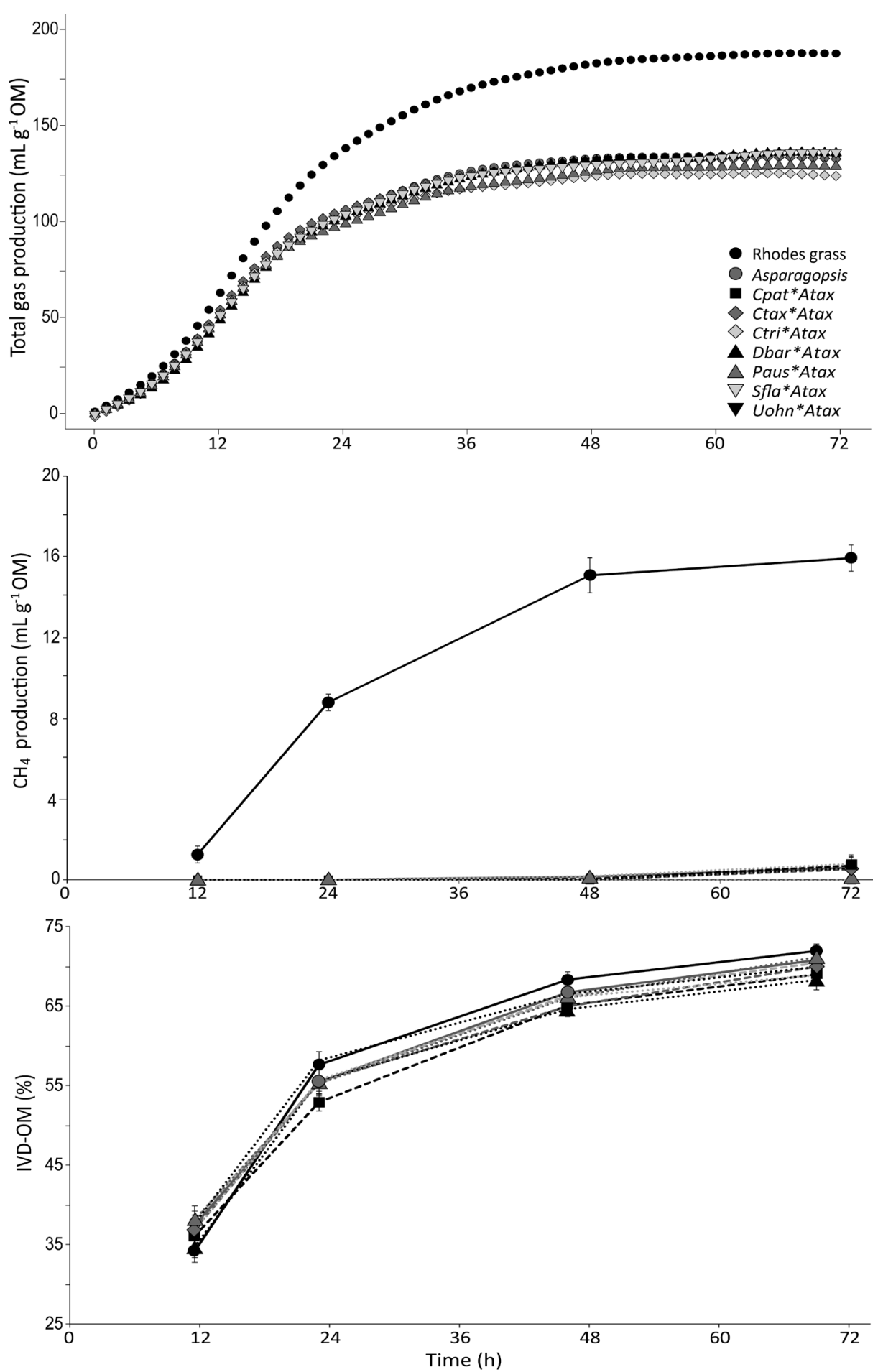

Figure 2. The effect of inclusion of seven different macroalgae combined with Asparagopsis on gas production and substrate digestibility over $72 \mathrm{~h}$ of in vitro fermentation with rumen fluid. From top down: Total gas production (TGP); $\mathrm{CH}_{4}$ production; and apparent in vitro digestibility (IVD-OM). The Rhodes grass control substrate was equal in all fermentations, the Asparagopsis control was included at a concentration of $2 \%$ of substrate OM, and the seven macroalgae combinations resulted in an inclusion of Asparagopsis at $\%$ and each of the seven macroalgae at $5 \%$. No \pm SE is presented for TGP because SE was smaller than the symbols. 
amounts were measured for the $S$. flavicans combination $\left(0.2 \mathrm{~mL} \cdot \mathrm{g}^{-1} \mathrm{OM}\right)$ representing $98 \%$ inhibition. After $48 \mathrm{~h}$ of fermentation $S$. flavicans and D. bartayresii combined with Asparagopsis accumulated small amounts of $\mathrm{CH}_{4}$ such that at $72 \mathrm{~h}$ of fermentation these two combinations had reduced $\mathrm{CH}_{4}$ by $95 \%\left(0.8 \mathrm{~mL} \cdot \mathrm{g}^{-1} \mathrm{OM}\right)$ compared to the Rhodes grass control $\left(16.0 \mathrm{~mL} \cdot \mathrm{g}^{-1} \mathrm{OM}\right)$. The Asparagopsis alone reduced $\mathrm{CH}_{4}$ by $99 \%$ $\left(0.2 \mathrm{~mL} \cdot \mathrm{g}^{-1} \mathrm{OM}\right)$ after $48 \mathrm{~h}$ and by $96 \%\left(0.6 \mathrm{~mL} \cdot \mathrm{g}^{-1} \mathrm{OM}\right)$ at $72 \mathrm{~h}$.

In the same way as Experiment 1 the typical pattern of IVD-OM increasing with time was demonstrated with or without macroalgae combinations (Figure 2). However, in Experiment 2 IVD-OM induced by the macroalgae combined with Asparagopsis was not as variable throughout the $72 \mathrm{~h}$ in vitro fermentations. Other than the Rhodes grass control, all fermentations contained 2\% Asparagopsis which negated effects of the other macroalgae in the combinations. All the fermentations coalesced from onset of fermentation and after $72 \mathrm{~h}$ of fermentation the IVD-OM ranged from a low of $68 \%$ to a high of $72 \%$ for the D. bartayresii combined with Asparagopsis and Rhodes grass control, respectively.

In Experiment 2, in vitro fermentations with inclusion of the seven macroalgae combinations or Asparagopsis induced significant reductions in TVFA $(P=0.002)$ and acetate $(P<0.001)$, and significant increases in propionate $(P<0.001)$ and butyrate $(P<$ $0.001)$ compared with the Rhodes grass control (Table 3 ). However, there was no significant difference between the Asparagopsis alone and the combinations, therefore improvements in VFA profiles due to combining Asparagopsis with any of the seven candidate macroalgae was not demonstrated. Compared with the Rhodes grass control, the macroalgae combinations induced reduction in TVFA on a molar concentration

Table 3. The effect of inclusion of seven macroalgae species combined with Asparagopsis on accumulation of volatile fatty acids after $72 \mathrm{~h}$ of in vitro fermentation with rumen fluid. The Rhodes grass control substrate was equal in all fermentations, the Asparagopsis P-control was included at $2 \%$ of substrate $\mathrm{OM}$, and the seven macroalgae combinations resulted in inclusions of Asparagopsis at $2 \%$ and each of the seven macroalgae at $5 \%$.

\begin{tabular}{ccccc}
\hline \multicolumn{5}{c}{ Volatile Fatty Acids $(\mathrm{mM})$} \\
\hline Treatment & Total & Acetate & Propionate & Butyrate \\
\hline Rhodes grass & $43.32 \pm 0.12^{\mathrm{a}}$ & $31.56 \pm 0.14^{\mathrm{a}}$ & $7.88 \pm 0.12^{\mathrm{a}}$ & $2.11 \pm 0.06^{\mathrm{a}}$ \\
Asparagopsis taxiformis & $37.26 \pm 1.10$ & $21.83 \pm 0.62$ & $9.60 \pm 0.19$ & $3.49 \pm 0.28$ \\
Caulerpa taxifolia ${ }^{\ddagger}$ & $40.29 \pm 0.87$ & $23.97 \pm 0.74$ & $9.98 \pm 0.10$ & $3.88 \pm 0.06$ \\
Cladophora patentiramea & $39.32 \pm 0.65$ & $23.38 \pm 0.33$ & $9.84 \pm 0.13$ & $3.76 \pm 0.24$ \\
Cystoseria trinodis & $38.77 \pm 1.16$ & $22.71 \pm 0.68$ & $9.91 \pm 0.36$ & $3.79 \pm 0.13$ \\
Dictyota bartayresii & $38.64 \pm 0.53$ & $23.09 \pm 0.27$ & $9.79 \pm 0.11$ & $3.54 \pm 0.21$ \\
Padina australis & $38.14 \pm 0.05$ & $22.69 \pm 0.24$ & $9.63 \pm 0.18$ & $3.57 \pm 0.18$ \\
Sargassum flavicans & $38.23 \pm 1.22$ & $22.46 \pm 1.10$ & $9.82 \pm 0.17$ & $3.58 \pm 0.15$ \\
Ulva ohnoi & $39.10 \pm 0.77$ & $23.52 \pm 0.85$ & $9.72 \pm 0.10$ & $3.54 \pm 0.21$ \\
\hline
\end{tabular}

a. Significant at $P<0.05$. Each of the seven macroalgae represents half of a combination pair with. 
basis from a low of $7 \%$ to a high of $12 \%$ and $14 \%$ by inclusion of the $P$. australis and $C$. taxifolia combined with Asparagopsis and Asparagopsis alone, respectively. The production of acetate was reduced by a low of $24 \%$ to a high of $29 \%$ and $31 \%$ by inclusion of S. flavicans and C. taxifolia combined with Asparagopsis, and Asparagopsis alone, respectively. Conversely, propionate was increased by a low of $21 \%$ to a high of $26 \%$ and $21 \%$ by inclusion of the P. australis and C. taxifolia combined with Asparagopsis, and Asparagopsis alone, respectively. The production of butyrate was increased by a low of $75 \%$ to a high of $91 \%$ and $72 \%$ for the $U$. ohnoi and C. taxifolia combined with Asparagopsis, and Asparagopsis alone, respectively.

\section{Discussion}

This report represents the only current study of these seven macroalgae species (Table 1) at low inclusion in vitro. The purpose of this study was to rank them for beneficial effects in vitro prior to selection of one candidate for evaluation in vivo. However, there was no clear ranking order based on $\mathrm{CH}_{4}$ mitigation and improvements in in vitro rumen fermentation. In combining the seven macroalgae with Asparagopsis there was no significant difference between the combinations and in all cases the Asparagopsis overwhelmed the effects on fermentation which eclipsed potential benefits of combining these macroalgae.

These macroalgae have been evaluated in rumen fermentations in vitro at high dose approaching $20 \%$ of substrate OM and the effects on TGP was variable and mostly significant reductions compared to controls were reported [13] [24]. In those studies the reductions in TGP were concomitant with reductions in $\mathrm{CH}_{4}$ and in some cases detrimental effect on IVD-OM. Fermentations with the individual (pure) macroalgae as inclusions with Rhodes grass in Experiment 1 of the present study also demonstrated variable TGP. However, lack of significant reduction can be attributed to the much lower inclusion concentration of $5 \%$ in the fermentations. It was hypothesized that the effect demonstrated at high dose would remain at 5\%, however only Asparagopsis at $2 \%$ maintained its potency at low dose which was a direct result of methanogenesis inhibition. The halogenated bioactive compounds inherent in Asparagopsis spp. have potent antimethanogenic properties [25] that are not inherent in the other macroalgae evaluated in the present study. Their mode of action at high dose may be attributed to organic acids, tannins, phlorotannins, polyphenoloics, aminoglycans and other compounds that have antibacterial or inhibitory effect on rumen microbial metabolism, but have minimal effect at a low dose.

The reduction in $\mathrm{CH}_{4}$ induced by these macroalgae has been reproduced at high inclusion concentrations in vitro [13] [24], unfortunately in the same way as TGP, at 5\% inclusion, the effect was minimal. However, the Asparagopsis at 2\% was consistent with previous studies specific to that macroalga demonstrating nearly complete elimination of $\mathrm{CH}_{4}$ production in vitro [10] [11]. Without significant differences in TGP and $\mathrm{CH}_{4}$ the ranking order was not clear and only numerical differences could be applied in the ranking. Thus, currently the Asparagopsis spp. are the only macroalgae demonstrating 
$\mathrm{CH}_{4}$ abatement ability exceeding $70 \%$ reduction at low dose and typically abatement > $99 \%$ is demonstrated.

Early in the fermentations the IVD-OM was variable with some of the macroalgae inducing a lag in the onset of fermentation. Previous research has shown a lag in TGP with addition at high dose [24] and this feature appears to be present at low dose, however both TGP and IVD-OM coalesced approaching $48 \mathrm{~h}$ of fermentation, and except for TGP induced by Asparagopsis, all fermentations were equal after $72 \mathrm{~h}$. The $A s$ paragopsis did not have different effect compared to the other macroalgae on IVD-OM demonstrating the importance of dose concentrations of macroalgae on rumen fermentation in vitro and presumably in ruminant animals. This indicates the importance of low dietary concentrations to maintain rumen efficiency and the seven macroalgae used in Experiment 1 demonstrated little benefit on IVD-OM or $\mathrm{CH}_{4}$ emissions at low dose. An important feature to note is that none of the macroalgae had a negative effect on IVD-OM at the dose concentration studied.

The effect of inclusion of antimethanogenic compounds on production of VFA during in vitro fermentations has been variable in most studies, however, a trend concomitant with significant $\mathrm{CH}_{4}$ reduction is in favour of increased propionate [26]. This has also been reported in previous studies using macroalgae which sometimes demonstrate a decrease in acetate in favour increased propionate and is more prominent with increasing dose. Macroalgae species that have a moderate or weak antimethanogenic capacity may not induce changes in the VFA profile [11] [27]. In the present study it was apparent that the seven macroalgae are weak antimethanogenic agents in vitro and as such they have minimal effects on VFA production. The TVFA and acetate results at $5 \%$ inclusion indicate a variable and small but not significant reduction with no apparent change in propionate or butyrate. These same macroalgae induced an increase in propionate with decreasing acetate at high dose, however, at high dose some species decreased TVFA as a result of detriment to IVD-OM [13]. It is important to maintain or improve IVD-OM to maximize fermentation efficiency which reiterates the requirement for appropriate dose concentrations of any dietary inclusion. Notably, Experiment 1 demonstrated that six of the seven macroalgae (excluding C. patentiramea) induced production of marginally more TVFA and significantly more acetate than $A s$ paragopsis and so demonstrated their potential to enhance fermentation efficiency when included in combination with Asparagopsis.

It was hypothesized that combining macroalgae with Asparagopsis in vitro would improve fermentation because these were identified in Experiment 1 as weakly antimethanogenic and resulted in some increase in VFA compared with Asparagopsis alone. However, at 5\% in combination with Asparagopsis at 2\% there was no evidence demonstrating improvements at a level to provide incentive for a follow-up in vivo study.

There was some variable but small decreases in TGP for some of the combinations compared with Asparagopsis alone, however all were significantly reduced compared to fermentations without macroalgae. The universal decrease in TGP was attributed to the 
Asparagopsis proportion of the combinations and a direct result of the near elimination of $\mathrm{CH}_{4}$ production. However, a minimal concentration of $\mathrm{CH}_{4}$ was detected in the final measurement $(72 \mathrm{~h})$ suggesting a gradual loss in antimethanogenic ability over time at the dose concentration used in this study. This phenomenon was described with $A s$ paragopsis at doses $\leq 2 \%$ of substrate OM [10]. In the present study this occurred with S. flavicans and D. bartayresii combined with Asparagopsis, however, this does not indicate an effect specific to these combinations as a minimal level of $\mathrm{CH}_{4}$ was detected after $72 \mathrm{~h}$ with the Asparagopsis alone. Total depletion of $\mathrm{CH}_{4}$ is not expected in vivo where rumen fermentation is much more robust than in batch cultures. Also, feed residence time in the rumen is typically less than $72 \mathrm{~h}$ [28].

The loss of energy as $\mathrm{CH}_{4}$ has potential to be reclaimed as productivity, however this can't be demonstrated in vitro and in vivo studies are necessary to determine the extent of productivity gains. When demonstrated in vivo productivity gains would dramatically increase the value of Asparagopsis and macroalgae combinations for livestock production systems. Adoption of any $\mathrm{CH}_{4}$ mitigation strategy requires more than environmental benefits. The value of carbon abatement may eventually provide revenue incentive for producers to adopt macroalgae feed additives based on $\mathrm{CH}_{4}$ abatement. However, improvements in productivity enhance the environmental value of macroalgae.

The IVD-OM was not negatively affected, however, the hypothesis of improvements to fermentation was not demonstrated by the combinations compared to Asparagopsis. All the fermentations, with and without macroalgae were stable and IVD-OM was not different. Improvements in IVD-OM would provide a conduit for improved utilization of feed and offset the cost of supplementation with macroalgae. Further investigation into macroalgae on improved feed energy utilization, productivity, and feed quality is necessary, particularly relative to periods of poor grass quality for grazing livestock [29].

In light of the VFA results of previous work [13] and Experiment 1 it was hypothesized that when combined with Asparagopsis the other macroalgae would have improved VFA production compared to the Asparagopis alone. This effect unfortunately was not demonstrated and the combinations adopted similar profiles as Asparagopsis alone and the variability between treatments observed in Experiment 1 was muted in Experiment 2, thus again demonstrating the dominant effect of Asparagopsis in vitro. It is typical with Asparagopsis that decrease in $\mathrm{CH}_{4}$ is concomitant with decrease in acetate and increase in propionate. It is common for antimethanogenic feed additives to have this effect in vitro [10] and in vivo [30] [31] and is believed to be due to reductive propionate production being more favourable than acetogenesis in the presence of excess hydrogen [26].

Although the present study did not support the use of macroalgae combinations to decrease $\mathrm{CH}_{4}$ production in vitro the utility of combinations of macroalgae to enhance ruminant animal productivity and reduce $\mathrm{CH}_{4}$ emissions is worthy of further exploration. Supplementation of high protein macroalgae such as the freshwater green Oe- 
dogonium sp. is feasible up to $25 \%$ of intake [11] which could increase the proportion of rumen bypass protein thus benefiting productivity [32]. Alternative sources of protein can also reduce $\mathrm{CH}_{4}$ emissions intensity by improving productivity of grass fed beef during those periods of decreasing diet quality. Supplementation with macroalgae can therefore directly reduce methanogenesis and reduce emission intensity by improving the product to emissions ratio.

\section{Conclusion}

There was not enough difference induced in rumen fermentation efficiency or $\mathrm{CH}_{4}$ production in vitro to support a conclusive ranking order between the seven individual macroalgae at the $5 \%$ inclusion concentration of this study. A numerical difference indicates $U$. ohnoi and $C$. patentiramea were the most and least antimethanogenic, respectively. When macroalgae were combined with Asparagopsis, a known potent antimethanogenic agent in vitro, there was not an adequate effect to justify proceeding to in vivo evaluation or recommendation for use of the combinations in livestock feed. However, high protein macroalgae supplemented at higher dietary concentrations may provide greater benefit when combined with Asparagopsis by contributing to reduced $\mathrm{CH}_{4}$ emissions through further improved productivity at times of low feed quality thus reducing emissions intensity per product output.

\section{Acknowledgements}

The gas and VFA analysis was accomplished via chromatography expertise of Shane Askew (Advance Analytical Centre, JCU) and collection and identification of macroalgae species assisted by Bjoern Gosch. Coral Coast Barramundi Fisheries Ltd. and Pacific Reef Fisheries Ltd. are acknowledged for supply of cultivated macroalgae. Melissa Matthews is acknowledged for reference management and construction of data tables.

\section{References}

[1] Beauchemin, K.A., Kreuzer, M., O’Mara, F. and McAllister, T.A. (2008) Nutritional Management for Enteric Methane Abatement: A Review. Australian Journal of Experimental Agriculture, 48, 21-27. http://dx.doi.org/10.1071/EA07199

[2] Kamra, D.N. (2005) Rumen Microbial Ecosystem. Current Science, 89, 124-135.

[3] Morgavi, D.P., Forano, E., Martin, C. and Newbold, C.J. (2010) Microbial Ecosystem and Methanogenesis in Ruminants. Animal, 4, 1024-1036. http://dx.doi.org/10.1017/S1751731110000546

[4] Patra, A.K. (2012) Enteric Methane Mitigation Technologies for Ruminant Livestock: A Synthesis of Current Research and Future Directions. Environmental Monitoring and Assessment, 184, 1929-1952. http://dx.doi.org/10.1007/s10661-011-2090-y

[5] Beauchemin, K.A., McAllister, T.A. and McGinn, S.M. (2009) Dietary Mitigation of Enteric Methane from Cattle.CAB Reviews. Perspectives in Agriculture, Veterinary Science, Nutrition and Natural Resources, 4, 1-18. http://dx.doi.org/10.1079/PAVSNNR20094035

[6] O’Sullivan, L., Murphy, B., McLoughlin, P., Duggan, P., Lawlor, P.G., Hughes, H. and Gardiner, G.E. (2010) Prebiotics from Marine Macroalgae for Human and Animal Health Ap- 
plications. Marine Drugs, 8, 2038-2064. http://dx.doi.org/10.3390/md8072038

[7] Evans, F.D. and Critchley, A.T. (2014) Seaweeds for Animal Production Use. Journal of Applied Phycology, 26, 891-899. http://dx.doi.org/10.1007/s10811-013-0162-9

[8] Rjiba Ktita, S., Chermiti, A. and Mahouachi, M. (2010) The Use of Seaweeds (Ruppia maritima and Chaetomorpha linum) for Lamb Fattening during Drought Periods. Small Ruminant Research, 91, 116-119. http://dx.doi.org/10.1016/j.smallrumres.2010.01.012

[9] Wang, Y., Xu, Z., Bach, S.J. and McAllister, T.A. (2008) Effects of Phlorotannins from Ascophyllum nodosum (Brown Seaweed) on in Vitro Ruminal Digestion of Mixed Forage or Barley Grain. Animal Feed Science and Technology, 145, 375-395.

http://dx.doi.org/10.1016/j.anifeedsci.2007.03.013

[10] Kinley, R.D., de Nys, R., Vucko, M.J., Machado, L. and Tomkins, N.W. (2016) The Red Macroalgae Asparagopsis taxiformis Is a Potent Natural Antimethanogenic That Reduces Methane Production during in Vitro Fermentation with Rumen Fluid. Animal Production Science, 56, 282-289. http://dx.doi.org/10.1071/AN15576

[11] Machado, L., Magnusson, M., Paul, N.A., Kinley, R.D., de Nys, R. and Tomkins, N.W. (2016) Dose-Response Effects of Asparagopsis taxiformis and Oedogonium sp. on in Vitro Fermentation and Methane Production. Journal of Applied Phycology, 28, 1443-1452. http://dx.doi.org/10.1007/s10811-015-0639-9

[12] Bergman, E.N. (1990) Energy Contributions of Volatile Fatty Acids from the Gastrointestinal Tract in Various Species. Physiological Reviews, 70, 567-590.

[13] Machado, L., Magnusson, M., Paul, N.A., de Nys, R. and Tomkins, N.W. (2014) Effects of Marine and Freshwater Macroalgae on in Vitro Total Gas and Methane Production. Plos One, 9, e85289. http://dx.doi.org/10.1371/journal.pone.0085289

[14] Horwitz, W. (2000) Official Methods of AOAC International. 17th Edition, Association of Official Analytical Chemists (AOAC) International, Gaithersburg.

[15] Angell, A.R., Mata, L., de Nys, R. and Paul, N.A. (2016) The Protein Content of Seaweeds: A Universal Nitrogen-to-Protein Conversion Factor of Five. Journal of Applied Phycology, 28, 511-524. http://dx.doi.org/10.1007/s10811-015-0650-1

[16] NHMRC (2013) Australian Code for the Care and Use of Animals for Scientific Purposes. 8th Edition, NHMRC, Canberra.

[17] Goering, H. and Van Soest, P. (1970) Forage Fiber Analyses (Apparatus, Reagents, Procedures, and Some Applications). Agriculture Handbook No. 379, U.S. Agricultural Research Service, Washington DC.

[18] Pellikaan, W.F., Hendriks, W.H., Uwimana, G., Bongers, L.J.G.M., Becker, P.M. and Cone, J.W. (2011) A Novel Method to Determine Simultaneously Methane Production during in Vitro Gas Production Using Fully Automated Equipment. Animal Feed Science and Technology, 168, 196-205. http://dx.doi.org/10.1016/j.anifeedsci.2011.04.096

[19] Tavendale, M.H., Meagher, L.P., Pacheco, D., Walker, N., Attwood, G.T. and Sivakumaran, S. (2005) Methane Production from in Vitro Rumen Incubations with Lotus pedunculatus and Medicago sativa, and Effects of Extractable Condensed Tannin Fractions on Methanogenesis. Animal Feed Science and Technology, 123-124, 403-419. http://dx.doi.org/10.1016/j.anifeedsci.2005.04.037

[20] Clarke, K.R. and Gorley, R. (2006) PRIMER v6: User Manual/Tutorial. PRIMER-E, Plymouth, 190.

[21] Anderson, M., Gorley, R. and Clarke, K. (2008) PERMANOVA+ for Primer: Guide to Software and Statistical Methods. PRIMER-E, Plymouth, 214.

[22] R Core Team (2013) R: A Language and Environment for Statistical Computing. R Founda- 
tion for Statistical Computing. Vienna. http://www.r-project.org

[23] López, S., Dhanoa, M.S., Dijkstra, J., Bannink, A., Kebreab, E. and France, J. (2007) Some Methodological and Analytical Considerations Regarding Application of the Gas Production Technique. Animal Feed Science and Technology, 135, 139-156.

http://dx.doi.org/10.1016/j.anifeedsci.2006.06.005

[24] Dubois, B., Tomkins, N.W., Kinley, R.D., Bai, M., Seymour, S., Paul, N.A. and de Nys, R. (2013) Effect of Tropical Algae as Additives on Rumen in Vitro Gas Production and Fermentation Characteristics. American Journal of Plant Sciences, 4, 34-43. http://dx.doi.org/10.4236/ajps.2013.412A2005

[25] Machado, L., Magnusson, M., Paul, N.A., Kinley, R.D., de Nys, R. and Tomkins, N.W. (2016) Identification of Bioactives from the Red Seaweed Asparagopsis taxiformis That Promote Antimethanogenic Activity. Journal of Applied Phycology, 28, 3117-3126. http://dx.doi.org/10.1007/s10811-016-0830-7

[26] Mitsumori, M., Shinkai, T., Takenaka, A., Enishi, O., Higuchi, K., Kobayashi, Y., Nonaka, I., Asanuma, N., Denman, S.E. and McSweeney, C.S. (2012) Responses in Digestion, Rumen Fermentation and Microbial Populations to Inhibition of Methane by a Halogenated Methane Analogue. British Journal of Nutrition, 108, 482-491. http://dx.doi.org/10.1017/S0007114511005794

[27] Kinley, R.D. and Fredeen, A.H. (2015) In Vitro Evaluation of Feeding North Atlantic Stormtoss Seaweeds on Ruminal Digestion. Journal of Applied Phycology, 27, 2387-2393. http://dx.doi.org/10.1007/s10811-014-0487-z

[28] Moran, J. (2005) How the Rumen Works. In: Moran, J., Ed., Tropical Dairy Farming. Feeding Management for Small Holder Dairy Farmers in the Humid Tropics, Landlinks Press, Melbourne, 41-49.

[29] Machado, L., Kinley, R.D., Magnusson, M., de Nys, R. and Tomkins, N.W. (2015) The Potential of Macroalgae for Beef Production Systems in Northern Australia. Journal of Applied Phycology, 27, 2001-2005. http://dx.doi.org/10.1007/s10811-014-0439-7

[30] Tomkins, N.W., Colegate, S. and Hunter, R. (2009) A Bromochloromethane Formulation Reduces Enteric Methanogenesis in Cattle Fed Grain-Based Diets. Animal Production Science, 49, 1053-1058. http://dx.doi.org/10.1071/EA08223

[31] Li, X., Norman, H.C., Kinley, R.D., Laurence, M., Wilmot, M., Bender, H., de Nys, R. and Tomkins, N.W. (2016) Asparagopsis taxiformis Decreases Enteric Methane Production from Sheep. Animal Production Science, AN15883. http://dx.doi.org/10.1071/an15883

[32] Poppi, D.P. and McLennan, S.R. (1995) Protein and Energy Utilization by Ruminants at Pasture. Journal of Animal Science, 73, 278-290. http://dx.doi.org/10.2527/1995.731278x 
Submit or recommend next manuscript to SCIRP and we will provide best service for you:

Accepting pre-submission inquiries through Email, Facebook, LinkedIn, Twitter, etc. A wide selection of journals (inclusive of 9 subjects, more than 200 journals)

Providing 24-hour high-quality service

User-friendly online submission system

Fair and swift peer-review system

Efficient typesetting and proofreading procedure

Display of the result of downloads and visits, as well as the number of cited articles

Maximum dissemination of your research work

Submit your manuscript at: http://papersubmission.scirp.org/

Or contact ajps@scirp.org 